\title{
FROM MEDIA LITERACY TO NEW MEDIA LITERACY: A LENS INTO OPEN AND DISTANCE LEARNING CONTEXT
}

\author{
Y. Zafer Can UGURHAN \\ ORCID: 0000-0003-1264-9002 \\ Faculty of Open Education \\ Anadolu University \\ Eskisehir, TURKEY \\ Dr. Evrim Genc KUMTEPE \\ ORCID: 0000-0002-2568-8054 \\ Faculty of Open Education \\ Anadolu University \\ Eskisehir, TURKEY \\ Dr. Alper Tolga KUMTEPE \\ ORCID: 0000-0002-2456-6338 \\ Faculty of Open Education \\ Anadolu University \\ Eskisehir, TURKEY \\ Abdullah SAYKILI \\ ORCID: 0000-0001-7754-6755 \\ Faculty of Open Education \\ Anadolu University \\ Eskisehir, TURKEY
}

Received: 14/11/2019 Accepted: 09/06/2020

\begin{abstract}
Media literacy, which traditionally aims to help individuals become better-informed users through proper consumption of media messages, has historically been reshaped to reflect the characteristics of the tools that individuals utilize to consume such messages. Information and Communication Tools (ICT) developed in the $21^{\text {st }}$ century, also referred to as the Digital Age, have enabled individuals to become producers of media messages in addition to consumers. Therefore, there has been a need for empirical studies into the concept of media literacy that has evolved into new media literacy with the impact of these new participatory and connective technologies. Within this regard, this study seeks to investigate the new media literacy levels of open and distance learners who primarily depend on ICT to access tertiary education. Besides, the study examines the relationship between demographic information of learners and their new media literacy skills.
\end{abstract}

Keywords: Media literacy, new media literacy, digital literacies, open and distance learning, online learning.

\section{INTRODUCTION}

Media, in the most general sense, refers to the mass communication tools and platforms. Media literacy, on the other hand, focuses on the utility of media messages including audio-visual and printed content via comprehension, analysis and critique of such messages (Buckingam, 2007). In this respect, media literacy comprises a set of multi-faceted skills that highlight the skills used by individuals to not only consume but also critically analyze what they have viewed, heard or read on the media platforms. Moreover, other key media literacy skills today include the production of self-generated content along with access, comprehension and critiquing skills. 
Media literacy traditionally aims to help individuals become better-informed users through proper consumption of media messages, which underscores a critical evaluation of media content by individuals (Scheibe, 2009). However, while the concept of media literacy emphasizes the role of the better-informed consumer of media messages, it falls short of encompassing the critical skills for individuals to actively produce and share self-generated media messages. Several factors including the rapid development of ICT, the blurring of the lines between time, place and tools for communication purposes, the transition from the industrial society to the digital (Christensen \& Tufte, 2010) as well as the evolution of web successively from 1.0, 2.0, 3.0 and now 4.0 which has added further characteristics into media tools and platforms have all contributed to the development of new dimensions for media literacy skills. Individuals extensively utilizing the new internet and social media tools in this age make use of newer sets of media skills required to function in these platforms such that today not only authority figures such as website owners or administrators but also "common folk" once holding the role of the consumer has gained the required tools to produce and publish content that reflect their own opinions, values and ideologies, which has blurred the distinctions between the sender and the receiver ends of the communication chain. All these technological and societal pressures require the reconceptualization of media literacies to include the new sets of skills that individuals make use of while functioning on the new media platforms which has become both popular and indispensable for the society today (Erstad, 2010). For these reasons, this study seeks to investigate the new media literacy levels of open and distance learners who primarily depend on ICT to access tertiary education. Besides, the study examines the relationship between demographic information of learners and their new media literacy skills.

\section{NEW MEDIA LITERACY}

The concept of new media which encompasses notions including digital interaction, creative and collective participation, connectivity, modularity, hybridity, data manipulation and virtuality represents technologybased socio-cultural platforms on which a given message is both created and distributed digitally by a given member of society. Within this respect, new media subsumes an information processing ecosystem in which digital messages are not only created but also accessed anytime, anywhere via any digital device (Chen, Wu \& Wang, 2011).

With the advent of Web 2.0 as an offset of the developing internet technologies, new media literacy has been attracting attention. Web 2.0 tools including but not restricted to internet-based social media platforms, blogs, wikis and RSS feeds hosts the power to facilitate production and distribution of knowledge on a global scale. The traditional approach to media literacy has undergone a transformation with Web 2.0 in such ways to expand to include "produce" and "distribute" skills as well as the traditional "access" and "consume". Therefore, the new media literacy framework highlights the interaction of individuals with others not only through consumption but also through production and distribution, which further allows the active participation in and co-production of media messages (Koc \& Barut, 2016). This collective process has also made it easier for individuals to share opinions and views. The developments experienced in the digital age has brought the production skills of individuals along with those of consumption to the fore. Thus, the concept of new media literacy, as a new phenomenon, refers to production, distribution and consumption of media messages via information and communication technologies through blending technical know-how and socio-cultural factors (Lin, Li, Deng \& Lee, 2013, p. 161).

The new outlook on the concept of new media necessitates mapping the boundaries of what entails to be "new media literate". For this reason, depending on the definitions and conceptualizations in the literature a new framework has been proposed (Chen et al., 2011; Lin et al., 2013; Lee et al., 2015). The framework developed by Chen et al. (2011) situates production in its focus in addition to consumption. Therefore, the new framework incorporates both the consumption skills which are regarded as sets of skills to access and use media messages with the help of various technical skills, and production skills with the advent and widespread use of Web 2.0 tools. This fundamental change in individuals' interaction with the media has made them both the consumer and the producer of such messages. In addition, Chen et al. (2011) has incorporated into the frame critical literacy skills referring to the awareness into both subtle and overt messages through analysis, evaluation and critique of media messages along with the traditional technical skills. (Chen et al., 2011). Lin et al. (2013) have revisited the framework and redrawn the boundaries of 
functional prosuming and consuming along with critical prosuming and consuming skills to compose the new media literacy skills, thereby proposing four sets of skills along functionality and criticality lenses (Lin et al., 2013, p. 165-166).

This study adopts the new media literacy framework developed by Lin et al. (2013) with Web 2.0 tools in mind and empirically tested by Lee et al. (2015) to investigate the new media literacy levels of open and distance learners. According to this framework, new media literacy is composed of four sets of skills including functional consumption (FC), critical consumption (CC), functional prosuming (FP), and finally critical prosuming $(\mathrm{CP})$. Figure 1 shows the framework.

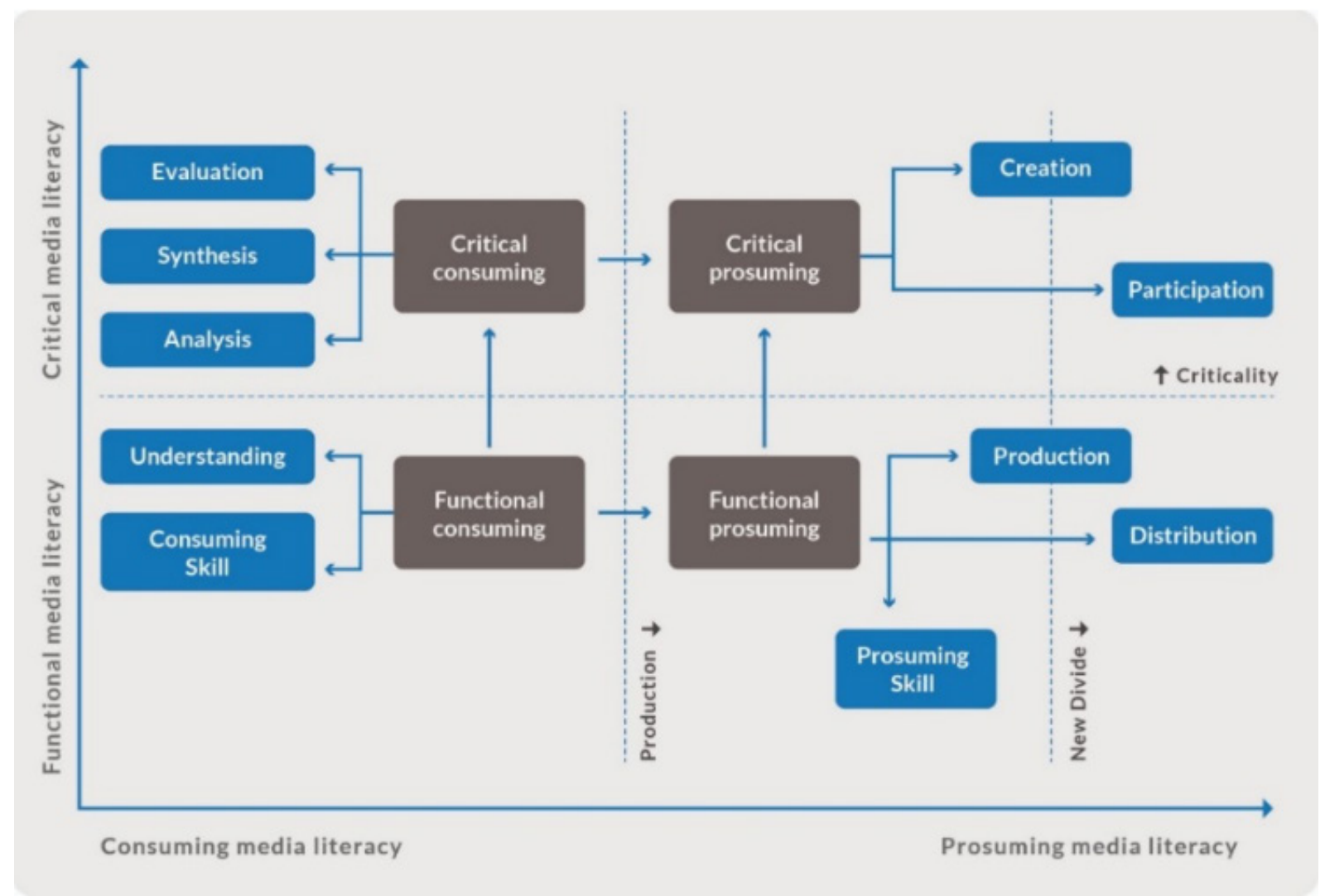

Figure 1. New Media Literacy Framework (Lin et al., 2013, p.163)

Functional consumption encompasses not only the technical know-how that individuals require to access and utilize media messages but also the skills required to make sense of these messages. Examples of this skills include individuals' use of computers to access information, search using search engines, and understand others' opinions located in various platforms (Lin et al., 2013, p. 164). Critical consumption, on the other hand, refers to sets of skills required to deconstruct and evaluate media messages being aware of the economic, political, cultural and social context these messages have been produced in. the critical consumption skills include those needed for an individual to be able to question the credibility of media messages through critiquing the content and the context. An individual's ability to analyze and evaluate the media messages through his/her own lens is another skill included in the critical consumption skillset (Chen et al., 2011, p. 86).

Functional prosuming skills refer to the technical know-how required to produce and distribute media content, replicate and reproduce different media forms such as text, image, audio and video (Lin et al., 2013). Examples of functional prosuming skills include signing up on a social media platform, sharing and distributing messages created by others on various platforms, and creating media messages in various forms including text, image, audio and video (Lee et al., 2015, p.85). However, critical prosumption involves the sets of skills for an individual to actively participate in social media platforms for creation of a collective culture, collaborating with others and creating unique media content reflecting his/her own sociocultural 
values and ideologies. An example would be composing a textual message on new media platforms or on social media with a critical standpoint conveying his/her own opinions and ideologies (Chen et al., 2011, p. 86; Lin et al., 2013, p.164).

\section{METHOD}

\section{Research Design}

This study employs cross-sectional quantitative research method to examine the new media literacy (NML) skills of open and distance learners studying at a state university in Turkey. The study also seeks to investigate the aforementioned skills depending on demographic information of these learners. In order to determine the NML skills the researchers used the NML Scale developed by Lee et al. (2015) and adopted into Turkish by Genc Kumtepe, Kumtepe, Ugurhan \& Saykili (2019).

The online version of the Turkish NML Scale, along with questions including demographic information, was shared on the learning management systems used by the university. A total of 1,862 learners completed the online self-report survey voluntarily. A data screening process and later normality assumption tests were conducted on the original dataset, which cleared the dataset off incomplete surveys and outliers. After these analyses, a total of 403 observations were removed from the dataset, which yielded 1,459 observations to carry out further analyses for the purposes of the study.

This study advances the preliminary search conducted by Genc Kumtepe et al., 2019 through incorporating further inferential statistics investigating the relationship between NML Skills and demographic information. Table 1 below briefly demonstrates the reliability and validity test results of the NML Scales developed by Scale developed by Lee et al. (2015) and adopted into Turkish by Genc Kumtepe et al. (2019), and Kara et al. (2018). The results validate the surveys as reliable and valid.

Table 1. The reliability and validity results of the NML Scales

\begin{tabular}{|c|c|c|c|c|c|c|c|c|c|}
\hline Skills & \# of Items & $x^{2}$ & df & $x^{2} / \mathrm{df}$ & AGFI & SRMR & RMSEA & CFI & Cronbach's a \\
\hline \multicolumn{10}{|c|}{ Lee et al. (2015) } \\
\hline $\mathrm{FC}$ & 6 & 21.43 & 9 & 2.38 & 0.97 & 0.02 & 0.05 & 0.95 & 0.88 \\
\hline $\mathrm{CC}$ & 13 & 198.02 & 62 & 3.19 & 0.92 & 0.06 & 0.06 & 0.73 & 0.88 \\
\hline $\mathrm{FP}$ & 13 & 177.99 & 62 & 2.87 & 0.93 & 0.05 & 0.06 & 0.73 & 0.91 \\
\hline $\mathrm{CP}$ & 5 & 11.92 & 5 & 2.38 & 0.98 & 0.02 & 0.05 & 0.98 & 0.72 \\
\hline \multicolumn{10}{|c|}{ Kara et al. (2018) } \\
\hline $\mathrm{FC}$ & 6 & 25.91 & 8 & 3.24 & - & 0.02 & 0.04 & 0.98 & 0.80 \\
\hline $\mathrm{CC}$ & 13 & 416.54 & 57 & 7.30 & - & 0.06 & 0.08 & 0.93 & 0.87 \\
\hline $\mathrm{FP}$ & 13 & 444.30 & 62 & 7.16 & - & 0.05 & 0.08 & 0.93 & 0.89 \\
\hline $\mathrm{CP}$ & 4 & 12.71 & 5 & 2.54 & - & 0.01 & 0.04 & 0.99 & 0.77 \\
\hline \multicolumn{10}{|c|}{ Genc Kumtepe et al. (2019) } \\
\hline $\mathrm{FC}$ & 6 & 15.59 & 9 & 1.73 & - & 0.02 & 0.03 & 0.99 & 0.76 \\
\hline $\mathrm{CC}$ & 13 & 197.29 & 41 & 4.81 & - & 0.04 & 0.07 & 0.95 & 0.86 \\
\hline $\mathrm{FP}$ & 13 & 177.28 & 40 & 4.43 & - & 0.04 & 0.06 & 0.96 & 0.90 \\
\hline $\mathrm{CP}$ & 5 & 11.78 & 4 & 2.94 & - & 0.02 & 0.05 & 0.99 & 0.79 \\
\hline \multicolumn{4}{|c|}{ Cutoff Values (Hu \& Bentler, 1999) } & $<5$ & $>0.85$ & $<0.05$ & $<0.08$ & $>0.95$ & $>0.70$ \\
\hline
\end{tabular}




\section{Participants}

The participants for this study was 1,459 open and distance learners studying for the various associate and undergraduate programs at a state university in Turkey. These learners volunteered to take part in the study. $35.2 \%(\mathrm{n}=514)$ of these learners were male and $64.8 \%(\mathrm{n}=945)$ were female. The ages of learners ranged from 18 to 71 , the age mean was $32.91(S D=10.69)$. Table 2 displays the age distribution of the learners, which indicates that the highest number of learners were in the 23-28 age group ( $\mathrm{n}=382 ; 26.20 \%)$, whereas, the lowest number of learners were in the 53 and above age group $(n=85 ; 5.8 \%)$.

Table 2. The age distribution of the participants

\begin{tabular}{ccc}
\hline Age Group & $\mathbf{n}$ & \% \\
\hline $18-22$ & 268 & 18.4 \\
$23-28$ & 382 & 26.2 \\
$29-34$ & 238 & 16.3 \\
$35-40$ & 207 & 14.2 \\
$41-46$ & 182 & 12.5 \\
$47-52$ & 97 & 6.6 \\
$53+$ & 85 & 5.8 \\
\hline
\end{tabular}

\section{RESULTS}

The results section of the study firstly presents both the descriptive statistics for both NML skills and the demographic information including gender, age, generation ( $\mathrm{X}$ and $\mathrm{Y}$ ), admission type, degree level, monthly income, occupation, internet usage and access to news. Furthermore, this section displays inferential statistics into the relationship between demographic information and NML skills.

\section{Demographic Information}

For the purposes of the study, several demographic information was collected. Table 3 below shows that the majority of the learners participating in the study was female (64.8\%). In terms of generations, most of the participants were of $Y$ generation, that is 39 and below $(n=1,062 ; 72.80 \%)$ while only $27.2 \%$ is of $X$ generation $(n=397)$. The results also revealed that a little more than half of the participants were $(53.1 \%)$ were enrolled in an associate degree, whereas the rest (46.9\%) was enrolled in an undergraduate degree.

After analyzing the admission data, the admission type was grouped into two; second university and others. Learners admitted through the second university are accepted without taking the nationwide compulsory university admission test because they have already completed or are still pursuing an undergraduate degree in a different program. The other option includes admissions types such as the nationwide university admission exam and transfer students.

The results show that even though both numbers are close, more participants $(52.2 \%)$ were admitted through second university than other admission types (47.8\%). Regarding the admission year, most participants were found to enroll at the university in the year 2018 (52.2\%), which is followed by learners between 2014 and 2017 (39\%) and lastly 2013 and before (8.8\%). In addition, a considerable number of participants reported they were employed in a part-time job $(\mathrm{n}=658 ; 45.1 \%)$, while $38.9 \%$ was unemployed. On the other hand, $5.6 \%$ of the participants were housewives and $4.9 \%$ was retired. In terms of monthly income, most participants had a monthly income of between 2001 and 4000 Turkish Lira (39.3\%) when only 3.7\% reported earning $500 \mathrm{TL}$ or below. Finally, most participants reported using the internet between 2 to 7 hours daily $(75.6 \%)$, while a few participants reported using the internet 1 hour or less $(8.2 \%)$ (Table 3 ). 
Table 3. The demographic information of the participants

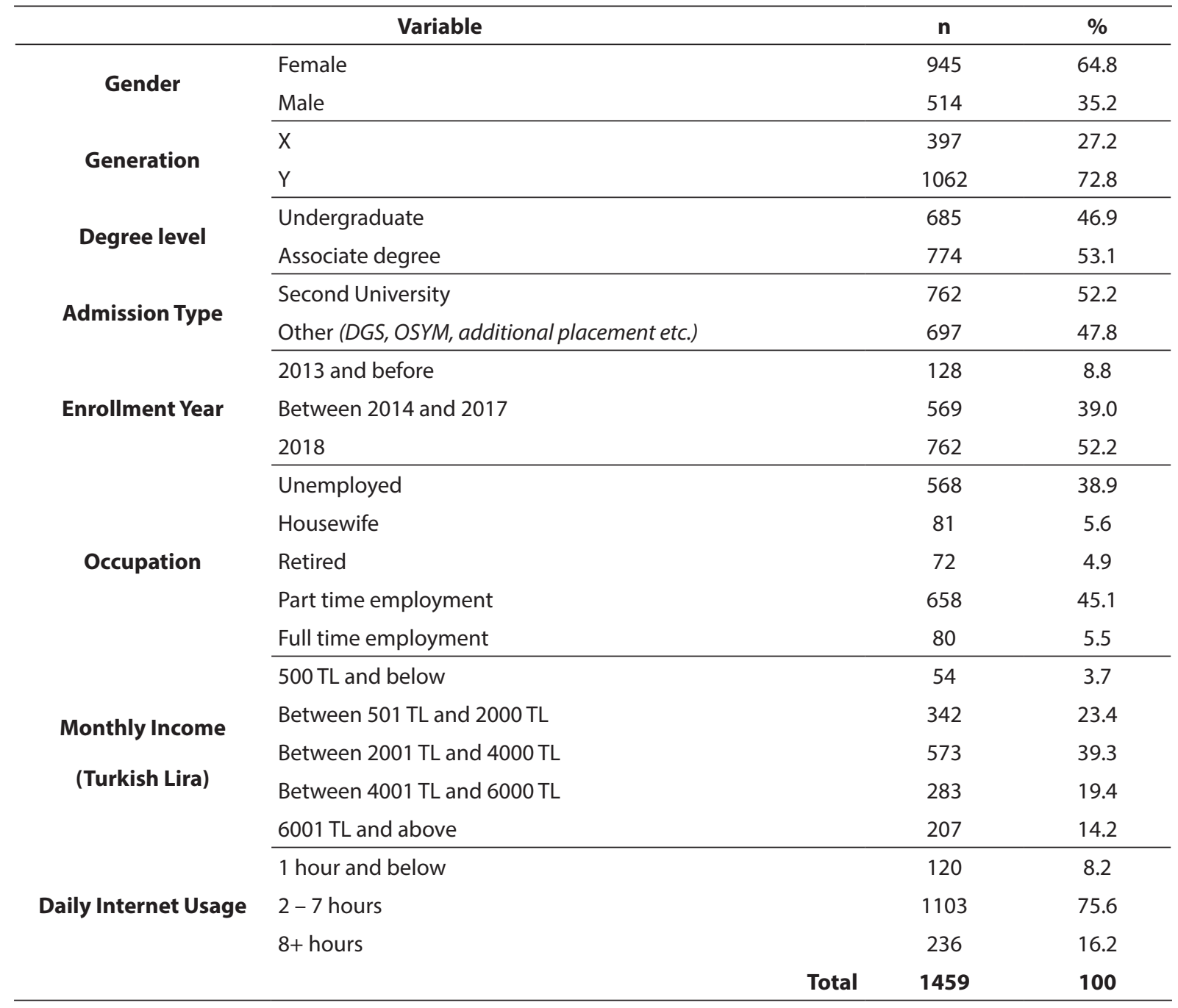

\section{Access to News}

The study also investigated how participants accessed news. The results revealed that the primary media participants access news were online platforms, i.e. news websites and social media. $82 \%$ of the participants reported accessing news on news websites often or very often, while $\% 76.4(\mathrm{n}=1,115)$ used social media to access news. On the other hand, it was found that \%53.4 ( $\mathrm{n}=779)$ of the participants accessed news on TV often or very often. Yet, similar numbers of participants reported reading newspapers seldom or listening to the radio seldom to access news (38.2\% \& 35.6\%, respectively) (see Table 4 below).

Table 4. The Platform and Frequency of Access to News

\begin{tabular}{ccccccc}
\hline \multicolumn{1}{c}{ Platform } & & Never & Seldom & Sometimes & Often & Very Often \\
\hline Newspaper & $\mathrm{n}(\%)$ & $269(18.4)$ & $558(38.2)$ & $448(30.7)$ & $117(8)$ & $67(4.6)$ \\
TV & $\mathrm{n}(\%)$ & $113(7.7)$ & $208(14.3)$ & $359(24.6)$ & $460(31.5)$ & $319(21.9)$ \\
Radio & $\mathrm{n}(\%)$ & $444(30.4)$ & $519(35.6)$ & $324(22.2)$ & $120(8.2)$ & $52(3.6)$ \\
Social Media & $\mathrm{n}(\%)$ & $46(3.2)$ & $102(7)$ & $196(18.4)$ & $466(31.9)$ & $649(44.5)$ \\
News Websites & $\mathrm{n}(\%)$ & $24(1.6)$ & $58(4)$ & $181(12.4)$ & $426(29.2)$ & $770(52.8)$ \\
\hline
\end{tabular}




\section{Descriptive Statistics for the New Media Literacy Scale}

Descriptive Statistics, including means and standard deviations, for the New Media Literacy Scale are displayed on Table 5 below.

Table 5. The descriptive statistics of the new media literacy scale $(\mathrm{n}=1,459)$

\begin{tabular}{ccc}
\hline Construct & Mean & Standard Deviation \\
\hline Functional Consuming (FC) & $\mathbf{4 . 6 7}$ & $\mathbf{0 . 4 4}$ \\
Critical Consuming (CC) & $\mathbf{4 . 3 5}$ & $\mathbf{0 . 5 5}$ \\
CC $\rightarrow$ Analysis & 4.34 & 0.70 \\
CC $\rightarrow$ Synthesis & 4.62 & 0.53 \\
CC $\rightarrow$ Evaluation & 4.08 & 0.79 \\
Functional Prosuming (FP) & $\mathbf{3 . 2 8}$ & $\mathbf{0 . 9 5}$ \\
FP $\rightarrow$ Distribution & 2.98 & 1.23 \\
FP $\rightarrow$ Production 1.0 & 3.36 & 1.19 \\
FP $\rightarrow$ Production 2.0 & 3.51 & 0.89 \\
Critical Prosuming (CP) & $\mathbf{2 . 9 1}$ & $\mathbf{1 . 0 6}$ \\
\hline
\end{tabular}

$(1=$ Strongly Disagree - $5=$ Strongly Agree; $1=$ Never $-5=$ Very Often $)$

The results of the descriptive statistics in to the NML skills of the open and distance learners taking part in the study revealed that the mean for the functional consuming $(\mathrm{FC})$ was $4.67(S D=0.44)$, for critical consuming $(C C) 4.35(S D=0.55)$, for functional prosuming $3.28(S D=0.95)$, and finally the mean for critical prosuming was $2.91(S D=1.06)$ (Table 5). Therefore, the results indicate that the participants have higher consuming skills in general than prosuming skills. As to the comparison between FC and CC skills, the results suggest higher FC skills than CC, albeit slightly. On the other hand, the level of difference FP and $\mathrm{CP}$ was wider in favor of FP. Consequently, the fact that the highest mean was achieved on FC, and the lowest on $\mathrm{CP}$ skills suggests that the participants were the most skilled at consuming media messages and the least developed skills belonged to those of critically prosuming such messages. This result is in line with Kara et al. (2018). Kara et al. (2018) investigated the NML skills of pre-service on-campus undergraduate teachers, and similarly their results revealed consuming skills than prosuming. However, in comparison open and distance learners in the context of this study were found to have higher consuming skills (i.e. FC and CC) than pre-service teachers in the context of Kara et al. (2018) ( $\mathrm{FC}=4.67$ vs 4.48 , and CC 4.36 vs 3.67, respectively). On the other hand, although the open and distance learners in this study had higher critical prosuming skills than pre-service teachers in Kara et al. (2018) $(\mathrm{CP}=2.91$ vs 2.47$)$, the open and distance learners had lower functional prosuming skills $(\mathrm{FP}=3.28$ vs 3.55$)$, which necessitates further inquiry into the issue.

The difference between consuming skills, both FC and CC, might be attributed to the fact that open and distance learners are required, by the nature of the delivery of education online, to extensively utilize several online learning resources for their studies to achieve their respected degree. Besides, since a considerable number of learners in the context of this study are aged between 23-28, which correspond to ages after obtaining an undergraduate degree, thus second university admission. These learners might have already developed both functional and critical skills throughout their earlier educational experiences during their first undergraduate degree. In yet another context, Chen et al. (2018) investigated the NML skills of K12 students. In line with the findings of this study and Kara et al. (2018), they found that K12 students had lower prosuming skills than consuming. Consequently, the results of these three studies (i.e. this study, Kara et al. 2018, and Chen et al. 2018) suggest that individuals primarily utilize consuming skills, which naturally develop over time, and prosuming skills are less developed since individuals do not refer to then extensively.

When critical consuming skills are further investigated, it was observed the highest mean for the skill levels achieved belonged to synthesis skills $(M=4.62 ; S D=0.53)$, which was followed successively by analysis $(M=$ $4.34 ; S D=0.70)$ and evaluation skills $(M=4.08 ; S D=0.79)$. Higher synthesis levels, which indicates better skills at meaningfully remixing and sampling media messages, could be the result of active participation in 
various social media platforms through exposure to various levels and forms of media messages. However, this issue needs further clarification through robust research designs including qualitative data. Furthermore, despite slightly lower means than synthesis skills, the analysis and evaluation skills are well developed in these participants considering the means for both these skills are over 4.0 in a 5-point scale. With respect to FP skills which were based on a five-point frequency scale, FP production 2.0 skills was observed to achieve a greater mean value $(M=3.51 ; S D=0.89)$ than FP production $1.0(M=3.36 ; S D=1.19)$ and FP distribution skills $(M=2.98 ; S D=1.23)$. The fact that the participants reported higher FPP 2.0 reveals that they not only remix an existing content or create their own but also share it on web 2.0 media platforms. Considering the ease with which the new social media platforms provide users technical tools and user-friendly interfaces to create and remix media content, the increased frequency of FPP 2.0 skills is only rational. On the other hand, lower FPP 1.0 scores signify the lack of need on the part of the participants to utilize offline authoring tools such as Photoshop, which require some level of at least semi-professional technical know-how, to create media messages in the existence of Web 2.0 tools which already make the authoring processes much easier to handle. The lowest mean score achieved on FP distributions skills implies that the participants in the context of this study do not choose to share/distribute media messages as much as produce such messages.

\section{New Media Literacy and Demographic Information}

In addition to establishing the NML skills of the open and distance learners participating in the study, this study furthermore seeks to investigate the relationship between NML skills, i.e. FC, CC, FP and CP skills, and demographic information including gender, age, generation (X and $\mathrm{Y}$ ), admission type, program level, monthly income, occupation, internet usage and access to news. For this purpose, IndependentSamples T-Test was conducted to examine whether NML skills differed significantly depending on gender, generation, admission type and program level. On the other hand, One-way ANOVA tests were used to examine the differences in terms of age, monthly income, occupation and time spent online. The following sections present the results of both t-tests and One-way ANOVA tests.

\section{Test Results}

When comparing genders, since homogeneity of variances was not achieved for FC $(p<0.05)$ using Levene's Test equal variances not assumed option was chosen. On the other hand, for CC, FP and CP skills homogeneity of variances was achieved $(p>0.05)$ equal variances assumed option was used. In terms of generation comparisons of X and $\mathrm{Y}$, homogeneity of variances was not achieved for FC, FP and CP $(p<0.05)$ while homogeneity of variances was achieved $(p>0.05)$ for CC. As to the admission type, homogeneity of variances was not achieved for CC, FP and CP $(p<0.05)$, however, variances was achieved $(p>0.05)$ for FC. Yet, for degree level (associate vs undergraduate) homogeneity of variances was achieved $(p>0.05)$ for all skill sets (Pallant, 2011). Table 6 below presents the results for the Independent-Samples t-Tests, which will be discussed in the proceeding sections separately. 
Table 6. The study of the NML skills in terms of gender, generation, admission type and degree level

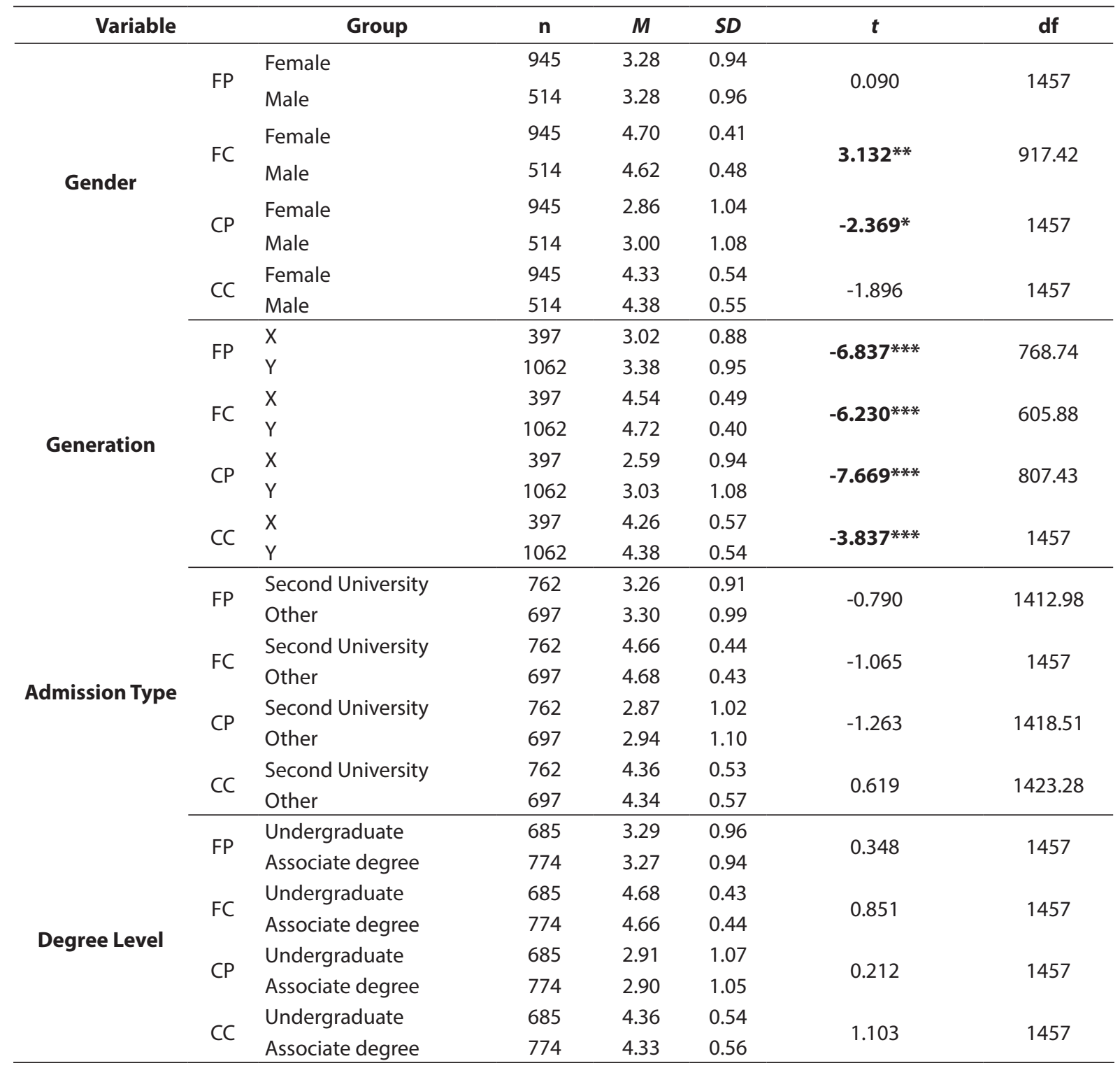

${ }^{* * *} p<0.001 ;{ }^{* *} p<0.01 ;{ }^{*} p<0.05$.

\section{New Media Literacy and Gender}

In terms of gender, the results of Independent-Samples T-Test, as seen on Table 6, revealed significant differences in $\mathrm{FC}(t=3.132 ; \mathrm{df}=917.42 ; p<0.01)$ and $\mathrm{CP}(t=-2.369 ; \mathrm{df}=1457 ; p<0.05)$. Notwithstanding, significant differences were not observed for FP and CC $(p>0.05)$. These results illustrate that in comparison with male participants, female participants achieved higher FC while male participants achieved higher scores in CP. Nonetheless, the results disclose similar scores for male and female participants in CC and FP skill sets. These results present both similarities and differences compared to the results Kara et al. (2018) report, who observed significant gender differences in all skill sets in favor of male participants. While their study showed higher skill sets for male participants, this study revealed significant differences in FC in favor of female participants and in CP in favor of male participants, which requires further investigation to unravel these differences. On the other hand, Chen et al. (2018) discovered no significant differences in terms of gender in their study conducted with K-12 student in Singapore. The discrepancies between the results of these studies might be attributed to contextual differences of educational level (tertiary vs K-12), delivery of education (online vs on-campus), and culture (Turkish vs Singaporean), however more empirical studies are needed to establish this proposition. 


\section{Generations $\mathrm{X}$ and $\mathrm{Y}$, and New Media Literacy}

The results pinpoint significant differences between generations $\mathrm{X}$ and $\mathrm{Y}$ for all four skill sets composing NML skills $(p<0.001)$ (Table 6). These results illustrate higher skills in favor of Generation Y (the younger generation) for NML skills (Figure 2), which is congruent with other research results (Chen et al., 2018; Arsenjevic \& Andevski, 2016). Literature also confirms that younger generations achieve higher NML skills compared to the older generations.
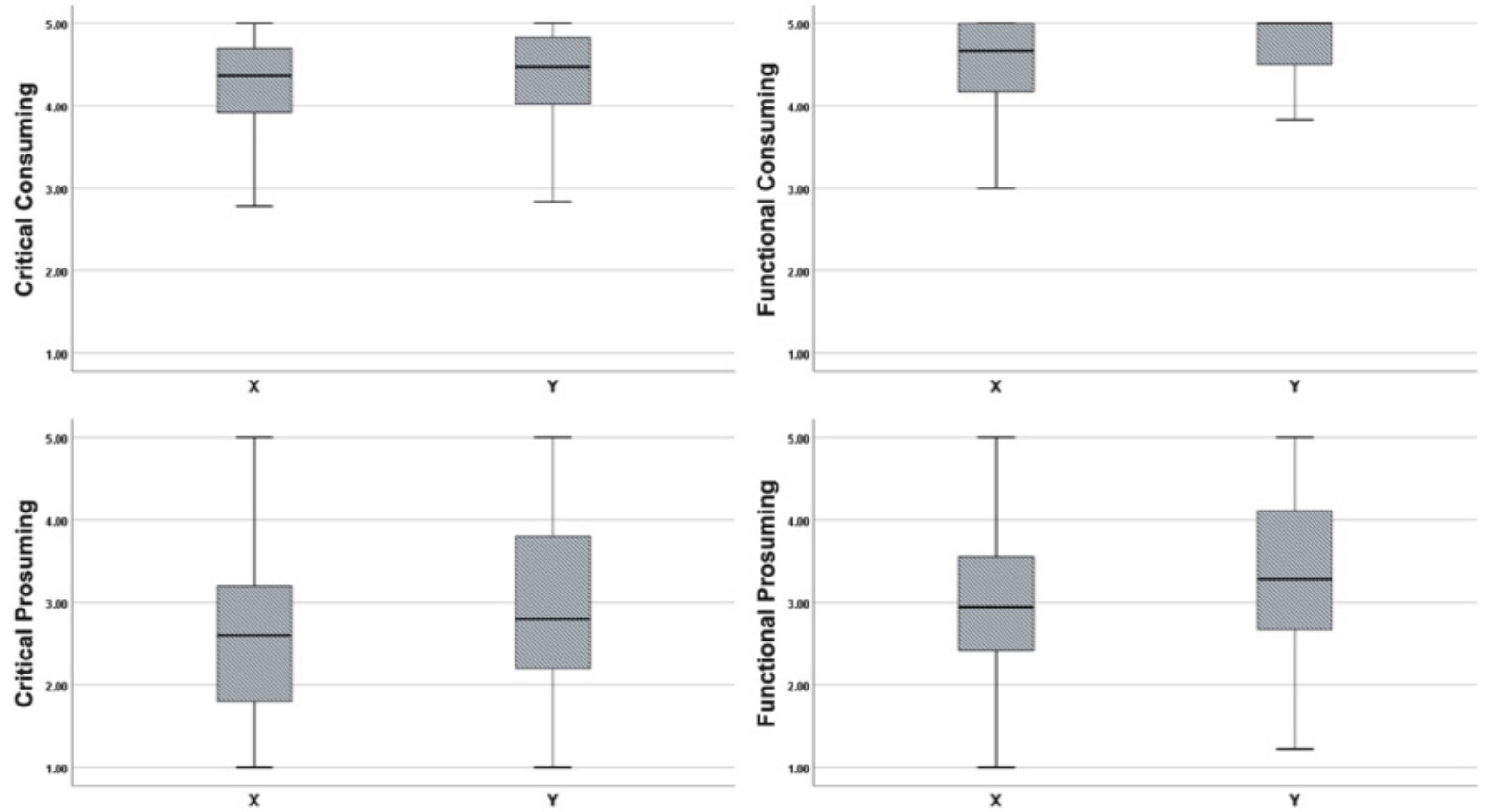

Figure 2. Generations X and Y, and New Media Literacy

\section{Admission Type, Degree Level and New Media Literacy}

Even though results revealed significant differences between generations, no significant differences were observed depending on admission type (second university and other) ( $p>0.05)$, which suggests similar NML levels for both admission types. Likewise, the results exhibit no significant differences in terms of degree level (associate and undergraduate) $(p>0.05)$. NML skills for both associate and undergraduate learners are at similar levels.

One-way ANOVA tests were used to examine the NML skill differences in terms of age, monthly income, occupation and time spent online. Since Levene's Test of homogeneity of variances was not achieved for FC, CC and FP $(p<0.05)$ regarding age, Brown-Forsythe statistic was used whereas ANOVA statistic was utilized for $\mathrm{CP}(p>0.05)$. In terms of monthly income, Brown-Forsythe statistic was used for CC and CP $(p<0.05)$, while $(p<0.05)$ ANOVA statistic was utilized for FC and FP $(p>0.05)$. As to comparisons for occupation, Brown-Forsythe statistic was used for CP and FC $(p<0.05)$, while $(p<0.05)$ ANOVA statistic was utilized for $\mathrm{CC}$ and FP $(p>0.05)$. For time spent online, Brown-Forsythe statistic was used for CC, CP and FC $(p<0.05)$, however, ANOVA statistic was utilized for FP ( $p>0.05)$ (Pallant, 2011). 
Table 7. Monthly income and NML Skills

\begin{tabular}{|c|c|c|c|c|c|c|}
\hline \multicolumn{2}{|c|}{ Variable } & Group & $\mathbf{n}$ & $M$ & $S D$ & $\boldsymbol{F}$ \\
\hline \multirow[b]{10}{*}{ Monthly } & \multirow{5}{*}{ FP } & $500 \mathrm{TL}$ and below & 54 & 3.49 & 1.02 & \multirow{5}{*}{0.769} \\
\hline & & Between 501 and $2000 \mathrm{TL}$ & 342 & 329 & 0.98 & \\
\hline & & Between $2001 \mathrm{TL}$ and $4000 \mathrm{TL}$ & 573 & 3.26 & 0.97 & \\
\hline & & Between $4001 \mathrm{TL}$ and $6000 \mathrm{TL}$ & 283 & 3.27 & 0.91 & \\
\hline & & $6001 \mathrm{TL}$ and above & 207 & 3.29 & 0.87 & \\
\hline & \multirow{5}{*}{ FC } & $500 \mathrm{TL}$ and below & 54 & 4.66 & 0.45 & \multirow{5}{*}{0.326} \\
\hline & & Between 501 and $2000 \mathrm{TL}$ & 342 & 4.66 & 0.44 & \\
\hline & & Between $2001 \mathrm{TL}$ and $4000 \mathrm{TL}$ & 573 & 4.66 & 0.45 & \\
\hline & & Between $4001 \mathrm{TL}$ and $6000 \mathrm{TL}$ & 283 & 4.69 & 0.41 & \\
\hline & & $6001 \mathrm{TL}$ and above & 207 & 4.68 & 0.41 & \\
\hline \multirow{10}{*}{ Income } & \multirow{5}{*}{ CP } & $500 \mathrm{TL}$ and below & 54 & 3.13 & 1.17 & \multirow[b]{2}{*}{0.773} \\
\hline & & Between 501 and $2000 \mathrm{TL}$ & 342 & 2.88 & 1.09 & \\
\hline & & Between $2001 \mathrm{TL}$ and $4000 \mathrm{TL}$ & 573 & 2.93 & 1.08 & \multirow{3}{*}{$\begin{array}{l}\text { Brown- } \\
\text { Forsythe }\end{array}$} \\
\hline & & Between $4001 \mathrm{TL}$ and $6000 \mathrm{TL}$ & 283 & 2.88 & 1.02 & \\
\hline & & $6001 \mathrm{TL}$ and above & 207 & 2.89 & 0.95 & \\
\hline & \multirow{5}{*}{ CC } & $500 \mathrm{TL}$ and below & 54 & 4.41 & 0.50 & \multirow[b]{2}{*}{1.748} \\
\hline & & Between 501 and 2000 TL & 342 & 4.29 & 0.59 & \\
\hline & & Between $2001 \mathrm{TL}$ and $4000 \mathrm{TL}$ & 573 & 4.35 & 0.55 & \multirow{3}{*}{$\begin{array}{l}\text { Brown- } \\
\text { Forsythe }\end{array}$} \\
\hline & & Between $4001 \mathrm{TL}$ and $6000 \mathrm{TL}$ & 283 & 4.36 & 0.54 & \\
\hline & & $6001 \mathrm{TL}$ and above & 207 & 4.41 & 0.47 & \\
\hline
\end{tabular}

Table 7 above demonstrates no significant differences between NML skills depending on monthly income $(p>0.05)$, which suggests that monthly income is not a factor contributing to higher or lower NML skills. This result is contradictory to Arsenijevic \& Andevski (2016) who reported significant differences in NML skills depending on monthly income in favor of higher income levels. However, the participants for their study also included university professors, which might explain the significant difference result since the open and distance learners participating in this study differ in terms of monthly income. The participants in this study are required to access and utilize online learning resources regardless of their monthly income, which might have contributed to leveling of NML skills for all participants. Besides, the age group, and the generation, most of the participants in this study belong to might have yielded to such results.

Table 8. Occupation and NML Skills

\begin{tabular}{|c|c|c|c|c|c|c|}
\hline \multicolumn{2}{|c|}{ Variable } & Group & $\mathbf{n}$ & $M$ & $S D$ & $\boldsymbol{F}$ \\
\hline \multirow{20}{*}{ 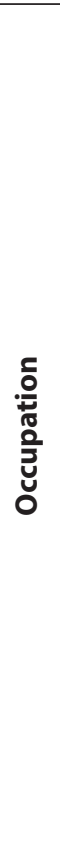 } & \multirow{5}{*}{ FP } & Unemployed & 568 & 3.35 & 0.97 & \multirow{5}{*}{$3.491 * *$} \\
\hline & & Housewife & 81 & 3.00 & 0.93 & \\
\hline & & Retired & 72 & 3.09 & 0.92 & \\
\hline & & Part time employment & 658 & 3.27 & 0.94 & \\
\hline & & Full time employment & 80 & 3.38 & 0.86 & \\
\hline & \multirow{5}{*}{ FC } & Unemployed & 568 & 4.71 & 0.40 & \multirow[b]{2}{*}{$3.764 * *$} \\
\hline & & Housewife & 81 & 4.66 & 0.45 & \\
\hline & & Retired & 72 & 4.50 & 0.54 & \multirow{3}{*}{$\begin{array}{l}\text { Brown- } \\
\text { Forsythe }\end{array}$} \\
\hline & & Part time employment & 658 & 4.66 & 0.45 & \\
\hline & & Full time employment & 80 & 4.65 & 0.44 & \\
\hline & \multirow{5}{*}{ CP } & Unemployed & 568 & 2.99 & 1.11 & \multirow[b]{2}{*}{$2.649 *$} \\
\hline & & Housewife & 81 & 2.68 & 0.95 & \\
\hline & & Retired & 72 & 2.72 & 0.98 & \multirow{3}{*}{$\begin{array}{l}\text { Brown- } \\
\text { Forsythe }\end{array}$} \\
\hline & & Part time employment & 658 & 2.89 & 1.04 & \\
\hline & & Full time employment & 80 & 2.86 & 0.96 & \\
\hline & \multirow{5}{*}{ CC } & Unemployed & 568 & 4.38 & 0.54 & \multirow{5}{*}{$2.466 *$} \\
\hline & & Housewife & 81 & 4.20 & 0.60 & \\
\hline & & Retired & 72 & 4.32 & 0.52 & \\
\hline & & Part time employment & 658 & 4.35 & 0.55 & \\
\hline & & Full time employment & 80 & 4.28 & 0.57 & \\
\hline
\end{tabular}


Table 8 above shows that the NML skills significantly differ $(p<0.05)$ depending on occupation; FP $(F=$ $3.491 ; p=0.008)$, FC $(F=3.764 ; p=0.005)$, CP $(F=2.649 ; p=0.033)$, and CC $(F=2.466 ; p=0.043)$. In order to investigate FP skills significantly differ depending on which occupations Tukey post-hoc test was carried out. The results suggest a significant difference between housewives and the unemployed $(\mathrm{md}=$ $0.34 ; p<0.05)$. The unemployed participants demonstrated higher CP. For FC, post-hoc Tamhane test results revealed a significant difference between the unemployed and the retired ( $\mathrm{md}=0.21 ; p<0.05$ ) in favor of the unemployed. Additionally, regarding CP skills, Tamhane tests demonstrated significant differences between the unemployed and the housewives ( $\mathrm{md}=0.30 ; p<0.05$ ), between the unemployed and the retired ( $\mathrm{md}$ $=0.26 ; p<0.05$ ), which implies that the unemployed participants report higher CP levels compared to the housewives and the retired. Furthermore, for CC skills Tukey post-hoc test signaled a significant difference between the unemployed and the housewives $(\mathrm{md}=0.18 ; p<0.05)$ in favor of the unemployed participants. The higher NML skills for the unemployed participants this study suggest that they might be spending more time online, which in return might have impacted positively on the development of NML skills since they do not necessarily have professional commitments to spare time for. Also, research report that the more time spent online, the higher NML skills (Literat, 2014). Apropos of time spent online and NML skills, Table 9 below presents One-way ANOVA test results examining the new media literacy skills in terms of time spent online.

Table 9. Time spent online and NML skills

\begin{tabular}{|c|c|c|c|c|c|c|}
\hline Variab & & Group & $\mathbf{n}$ & $M$ & $S D$ & $\boldsymbol{F}$ \\
\hline \multirow{12}{*}{$\begin{array}{l}\text { Time Spent } \\
\text { Online }\end{array}$} & \multirow{3}{*}{ FP } & 1 hour or less & 120 & 2.81 & 1.03 & \multirow{3}{*}{$34.332 * * *$} \\
\hline & & $2-7$ hours & 1103 & 3.25 & 0.91 & \\
\hline & & $8+$ hours & 236 & 3.64 & 0.94 & \\
\hline & \multirow{3}{*}{ FC } & 1 hour or less & 120 & 4.54 & 0.52 & \multirow{3}{*}{$\begin{array}{l}\mathbf{8 . 6 5 2}^{* * *} \text { Brown- } \\
\text { Forsythe }\end{array}$} \\
\hline & & $2-7$ hours & 1103 & 4.67 & 0.43 & \\
\hline & & $8+$ hours & 236 & 4.75 & 0.40 & \\
\hline & \multirow{3}{*}{$\mathrm{CP}$} & 1 hour or less & 120 & 2.44 & 1.12 & \multirow{3}{*}{$\begin{array}{c}\quad \mathbf{2 5 . 7 4 7 * * *} \\
\text { Brown-Forsythe }\end{array}$} \\
\hline & & $2-7$ hours & 1103 & 2.88 & 1.02 & \\
\hline & & $8+$ hours & 236 & 3.29 & 1.10 & \\
\hline & \multirow{3}{*}{ CC } & 1 hour or less & 120 & 4.13 & 0.65 & \multirow{3}{*}{$\begin{array}{c}16.532 * * * \text { Brown- } \\
\text { Forsythe }\end{array}$} \\
\hline & & $2-7$ hours & 1103 & 4.34 & 0.54 & \\
\hline & & $8+$ hours & 236 & 4.50 & 0.51 & \\
\hline
\end{tabular}

${ }^{* * *} p<0.001$.

The results presented on Table 9 reveals significant differences in NML skills depending on time spent online $(p<0.001)$. In order to determine among which groups was a significant difference, Tukey post hoc tests were utilized. The results demonstrated significant differences in terms of FP skills between participants spending 1 hour or less and participant spending $2-7$ hours online ( $\mathrm{md}=-0.44 ; p<0.001)$, and 8 hours or more online ( $\mathrm{md}=-0.83 ; p<0.001$ ). A significant difference was also observed between participants spending $2-7$ hours and 8 hours or more online $(\mathrm{md}=-0.39 ; p<0.001)$. Furthermore, for FC skills Tamhane posthoc test results showed significant differences between participants spending 1 hour or less and participant spending $2-7$ hours online ( $\mathrm{md}=-0.12 ; p<0.05$ ), and 8 hours or more online $(\mathrm{md}=-0.21 ; p<0.001)$. Likewise, a significant difference was also detected between participants spending $2-7$ hours and 8 hours or more online ( $\mathrm{md}=-0.08 ; p<0.05)$. As for CP skills, Tamhane post-hoc test results demonstrated significant differences between participants spending 1 hour or less and participant spending $2-7$ hours online $(\mathrm{md}=$ $-0.43 ; p<0.001)$, and 8 hours or more online ( $\mathrm{md}=-0.85 ; p<0.001$ ). Moreover, a significant difference was 
also detected between participants spending $2-7$ hours and 8 hours or more online $(\mathrm{md}=-0.41 ; p<0.001$ ). Similarly, regarding CC skills Tamhane post-hoc test results demonstrated significant differences between participants spending 1 hour or less and participant spending $2-7$ hours online ( $\mathrm{md}=-0.21 ; p<0.01$ ), and 8 hours or more online ( $\mathrm{md}=-0.36 ; p<0.001$ ). Besides, a significant difference was also detected between participants spending $2-7$ hours and 8 hours or more online $(\mathrm{md}=-0.15 ; p<0.001)$. The significant difference results in all four NML skill sets in terms of all groups of time spent online indicate that increased time spent online contributes to the development of NML skills. Widespread use of innovative Web 2.0 tools allowing individuals to easily create and share content as well as connect with each other on several levels enables such NML skills to flourish among individuals spending time on them. Furthermore, the ubiquity of such tools boosting the creation and distribution of new media content on several devices increasing mobility of individuals encourages them to spend more time online, which in turn equips individuals with opportunities to test and enhance NML skills (Figure 3).
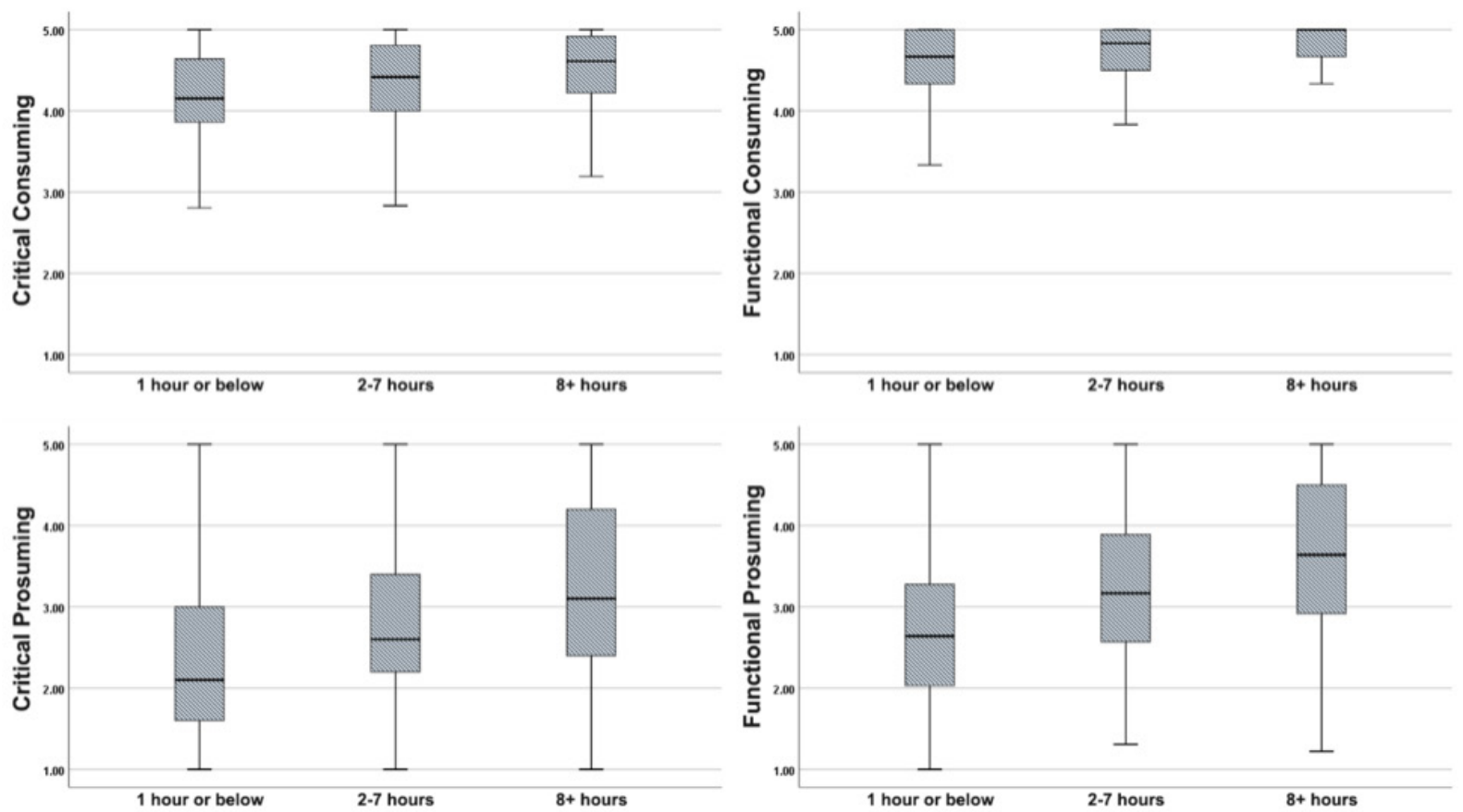

Figure 3. Time spent online and NML skills

\section{Access to News and NML Skills}

In this study, data regarding the media platforms the participants access news along with the frequency of access was gathered in order to investigate whether NML skills differed depending on the platform and frequency of access to news. Line graphs below show that in general the higher the frequency of access to news on each platform, the higher NML skills of the participants (Figure 4). On the other hand, although consuming skills (i.e. FC and CC) increased relatively gradually depending on the frequency of access to news on each platform, significant increase was observed for prosuming skills (i.e. FP and CP) for each platform depending on frequency of access. 

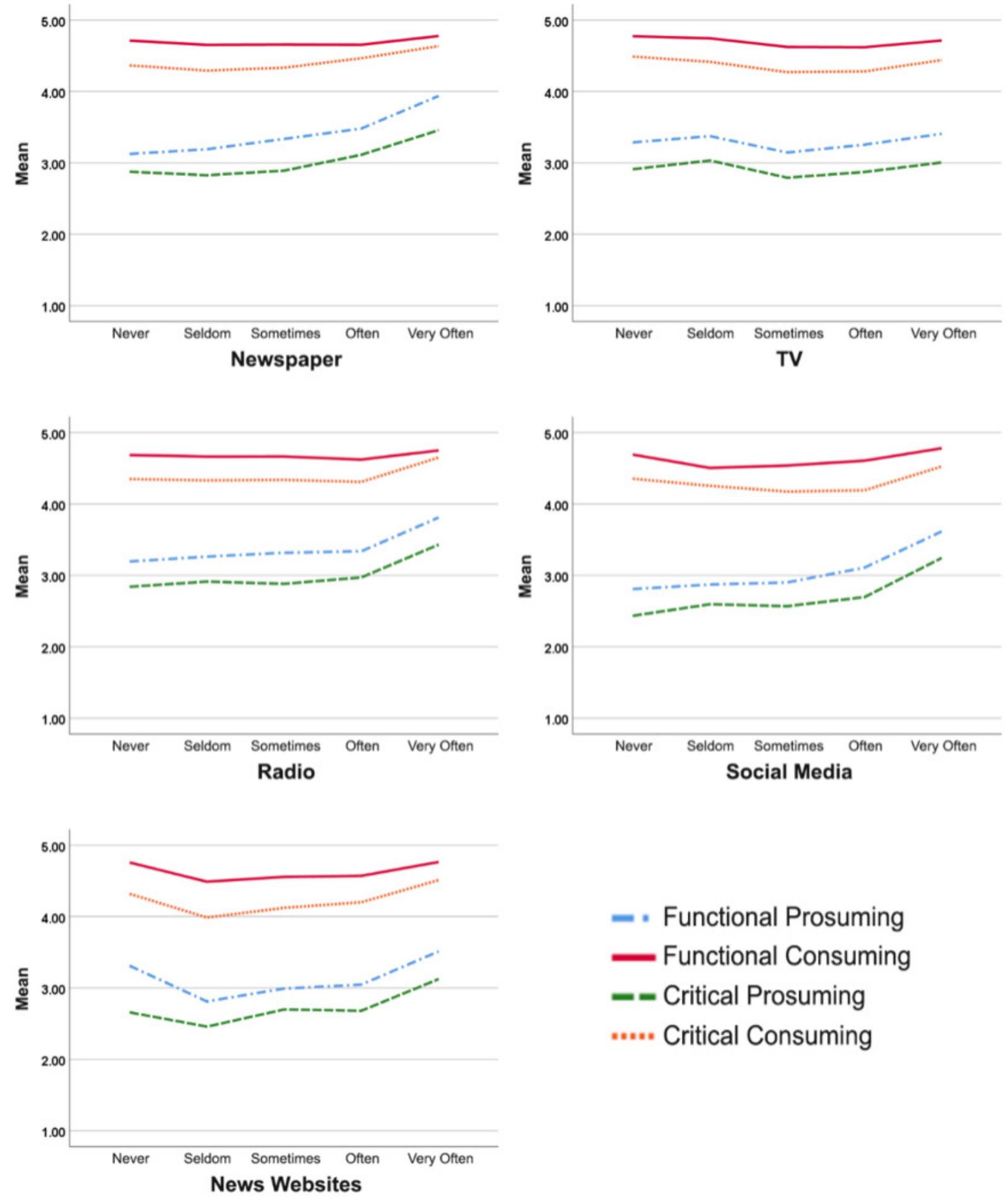

Figure 4. Access to News and New Media Literacy Skills

\section{DISCUSSION AND CONCLUSION}

The concept of media literacy has continuously been shaped and reshaped by the tools people use to consume and produce media messages to make up for the communication needs. Media literacy, which traditionally focusses on enabling individuals to become better-informed consumers of media messages, has undergone dramatic changes historically to reflect the characteristics of the tools used to consume or produce such messages. What has begun as making sense of symbols carved on basically stationary media such as stone tablets, has been transformed into a complex venture involving digital text, images and moving pictures in addition to digital tools promoting distribution of messages and enhancing digital connectivity 
and sociality in the $21^{\text {st }}$ century? Therefore, the traditional conceptualizations of media literacy have today fallen short in explicating what it entails to be a media literate individual in the digital age. Within this respect, the proposed framework to map the boundaries of new media literacy needs to be empirically tested for validity in multiple contexts. For these reasons, this study sought to investigate the validity of the NML framework within the context of open and distance learning institution since the delivery of education solely depends on such digital tool which requires the participants of this study to utilize the drivers of new media consumption and production. In addition to examining the NML skill levels of the participants, this study aimed to inspect such skills in terms of demographic information.

The results revealed that the participants had higher scores for consumption skills (FC and CC) than prosuming skills (FP and $\mathrm{CP}$ ), which signifies that the participants in this context utilize consuming skills more than prosuming. This could be attributed to the fact that the participants in this context are primarily required to "consume" the learning resources they have been provided online. However, more in-depth studies adopting comprehensive data resources including qualitative and quantitative data might help find empirical propositions into the reasons for this occurrence.

Regarding demographic information and NML skills, the results showed significant differences between genders in terms of FC and $\mathrm{CP}$ while no such significant differences were observed for FP and CC skill sets. Specifically, the data suggested that female participants achieved higher FC skills than males, whereas, male participants scored higher on CP. Also, the results demonstrated significant differences between generations $\mathrm{X}$ and $\mathrm{Y}$ for all four skill sets composing NML skills in favor of Generation Y. Furthermore, the results revealed significant differences depending on occupation. The higher NML skills for the unemployed participants in comparison with other occupation groups this study suggest that they might be spending more time online, which in return might have impacted positively on the development of NML skills since they do not necessarily have professional commitments to spare time for. Similarly, the significant difference results in all four NML skill sets in terms of all groups of time spent online indicate that increased time spent online contributed to the development of NML skills. Lastly, the investigation of frequency of access to news in addition to the news access platforms showed regardless of platform the higher frequency of access to news, the higher NML skills. However, despite significant difference results in the aforementioned demographic information, the results demonstrated no significant differences in terms of admission type, degree level and monthly income. Further studies utilizing both quantitative and qualitative data need to be conducted to unravel the reasons for significant differences found in this study. In addition, the relationship between NML skills and other demographic variables excluded in this study such as program and the courses taken. Finally, the comparison of the NML skills of on-campus students and open and distance learners will contribute to understanding the impact of delivery mode on NML skills.

\section{BIODATA and CONTACT ADDRESSES of AUTHORS}

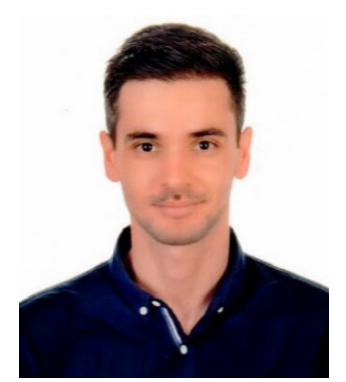

Y. Zafer Can UGURHAN holds a master's degree in communication sciences, and he is pursuing his $\mathrm{Ph} . \mathrm{D}$. in the same department. He is currently a faculty member in the department of Learning Technologies Research and Development at Open Education Faculty, Anadolu University. His research interest covers advertising theory, quantitative research methods and design, multivariate statistics, structural equation modeling, and he has published articles in national and international journals.

\section{Y. Zafer Can UGURHAN}

Learning Technologies Research and Development Department, Faculty of Open Education Address: Anadolu University, Yunus Emre Campus, 26470, Eskisehir, Turkey

Phone: +902223350580 / Ext. 5619

E-mail: yzcu@anadolu.edu.tr 


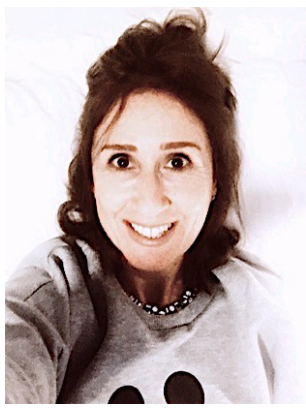

Dr. Evrim GENC KUMTEPE received her masters and doctorate degrees in the Program of Science Education at Florida State University (FSU), USA. She also holds a minor degree from the Program of Measurement and Statistics from FSU. Her primary research interests include science and technology in distance education. She is presently working as an associate professor at the Faculty of Open Education, Anadolu University, Turkey. She has been teaching science education courses in the field of early childhood and also statistics and research method courses both at the undergraduate and graduate levels. She currently serves as the Head of Continuing Education Department and the Coordinator of the Internship and Practicum Courses Office at Open Education System.

\section{Evrim GENC KUMTEPE}

Department of Continuing Education, Faculty of Open Education

Address: Anadolu University, Yunus Emre Campus, 26470, Eskisehir, Turkey

Phone: +902223350580

E-mail: egkumtepe@anadolu.edu.tr

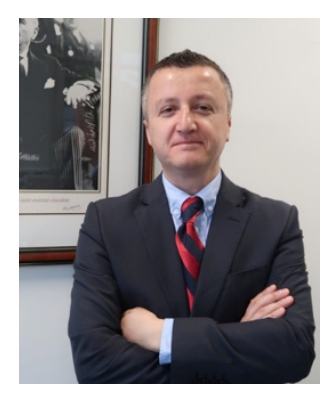

Dr. Alper Tolga KUMTEPE earned his BSc degree in Educational Communications in 1995 at Anadolu University. He then completed his MS degree in 2000 and Ph.D. degree in 2005 at the Florida State University, USA. He worked as a researcher at the Florida Center for Reading Research. He is currently working as a Professor at the College of Open Education, Anadolu University, Turkey. His research interests include e-learning, measurement and evaluation, motivation in distance learning, and quantitative research methods. He served as the Principal Investigator and researcher in numerous online learning projects including 7 projects funded by EU. He also presented and published scholarly articles in the field open and distance education.

\section{Alper Tolga KUMTEPE}

Department of Distance Education, Faculty of Open Education

Address: Anadolu University, Yunus Emre Campus, 26470, Eskisehir, Turkey

Phone: +902223350580

E-mail: atkumtepe@anadolu.edu.tr

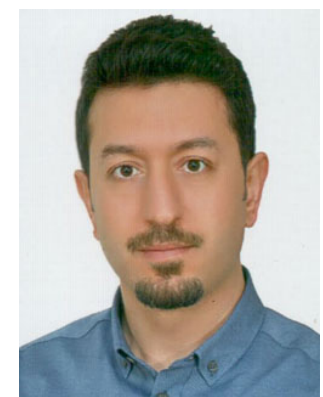

Abdullah SAYKILI received his BA in English Language Teaching and MA in Distance Education. He's currently pursuing his $\mathrm{PhD}$ in Distance Education at Anadolu University, Turkey. He worked as an English language instructor in secondary and tertiary levels for thirteen years. He is currently a faculty member at the department of Learning Technologies Research and Development at Open Education Faculty, Anadolu University. His research interests include open and distance learning, multiculturality, culture in online environments, social media and learning, and foreign language learning and teaching.

\section{Abdullah SAYKILI}

Department of Distance Education, Faculty of Open Education

Address: Anadolu University, Yunus Emre Campus, 26470, Eskisehir, Turkey

Phone: +902223350580

E-mail: asaykili@anadolu.edu.tr 


\section{REFERENCES}

Arsenijevic, J., \& Andevski, M. (2016). New media literacy within the context of socio-demographic characteristics. Procedia Technology, 22, 1142-1151. doi: 10.1016/j.protcy.2016.01.161

Buckingham, D. (2007). Digital media literacies: rethinking media education in the age of the internet. Research in Comperative and International Education, 1(2), 43-55. doi: 10.2304/rcie.2007.2.1.43

Chen, D. T., Wu, J., \& Wang, Y. M. (2011). Unpacking new media literacy. Journal of Systemics, Cybernetics and Informatics, 9(2), 84-88. Retrieved from http://www.iiisci.org/journal/sci/FullText. asp? $\mathrm{var}=\& \mathrm{id}=\mathrm{OL} 508 \mathrm{KR}$

Chen, D.-T., Lin, T.-B., Li, J.-Y., \& Lee, L. (2018). Establishing the norm of new media literacy of Singaporean students: Implications to policy and pedagogy. Computers \& Education, 124, 1-13. doi: 10.1016/j.compedu.2018.04.010

Christensen, O., \& Tufte B. (2010). Media education - between theory and practice, p.109-121. In Media Literacy Education Nordic Perspectives (Eds: S. Kotilainen, Arnolds-Granlund, S.). Sweden: Nordicom, Goteborg.

Erstad, O. (2010). Media literacy and education: the past, present and future, p.15-29 In Media Literacy Education Nordic Perspectives, (Eds: S. Kotilanien, Arnolds-Granlund, S.). Sweden:Nordicom, Goteborg.

Genc Kumtepe, E., Kumtepe, A., Ugurhan, Y. Z. C., \& Saykili, A. (2019). Investigating the new media literacy skills of open and distance learners. C. Erdem, H. Bagci ve M. Kocyigit (Eds). In 21st Century Skills and Education (pp.112-137). Newcastle: Cambridge Scholars Publishing.

Hu, L.-t., \& Bentler, P. M. (1999). Cutoff criteria for fit indexes in covariance structure analysis: Conventional criteria versus new alternatives. Structural Equation Modeling: A Multidisciplinary Journal, 6(1), 1-55. doi: 10.1080/10705519909540118

Kara, M., Caner, S., Gokben, A. G., Cengiz, C., Simsek, E. I., \& Yildirim, S. (2018). Validation of an instrument for preservice teachers and an investigation of their new media literacy. Journal of Educational Computing Research, 56(7), 1005-1029. doi: 10.1177/0735633117731380

Koc. M., \& Barut, E. (2016). Development and validation of New Media Literacy Scale (NMLS) for university students. Computers in Human Behavior, 63, 834-843. doi: 10.1016/j.chb.2016.06.035

Lee, L., Chen, D., Li, J., \& Lin, T. (2015). Understanding new media literacy: The development of a measuring instrument. Computers \& Education, 85(1), 84-93. doi: 10.1016/j.compedu.2015.02.006

Lin, T.-B., Li, J.-Y., Deng, F., \& Lee, L. (2013). Understanding new media literacy: An explorative theoretical framework. Educational Technology \& Society, 16(4), 160-170. Retrieved from www.jstor.org/ stable/jeductechsoci.16.4.160

Literat, I. (2014). Measuring new media literacies: Towards the development of a comprehensive assessment tool. Journal of Media Literacy Education, 6(1), 15-27. Retrieved from https://digitalcommons.uri. edu/jmle/vol6/iss $1 / 2$

Pallant, J. (2011). SPSS survival manual: A step by step guide to data analysis using SPSS (4th ed.). New York: Open University Press.

Scheibe, C. (2009). Sound great, but I don't have time helping teachers meet their goals and needs with media literacy education. Journal of Media Literacy Education, 1(1), 68-71. Retrieved from https:// digitalcommons.uri.edu/jmle/vol1/iss $1 / 6$ 